\title{
Hopelessness and HIV infection: an exploratory study with a gender-specific perspective
}

\author{
Lena Nilsson Schönnesson 1,8*, Michael W. Ross², Diego Garcia-Huidobro ${ }^{3}$, Lars E. Eriksson ${ }^{4,5,6}$, Galit Andersson',
} Mark L. Williams ${ }^{7}$ and Anna-Mia Ekström ${ }^{1,6}$

\begin{abstract}
Background: An understudied psychological response to HIV-related stressors among people living with HIV is hopelessness. Hopelessness is the expectation that things will not improve and feeling helpless to change one's current situation. The aim of this study was to assess prevalence and levels of hopelessness and its direct and indirect contributors in people living with HIV in Sweden.

Methods: Participants included 967 women and men from the "Living with HIV in Sweden" cross-sectional study with available data regarding hopelessness measured by the Beck Hopelessness Scale. Binary and multiple logistic regression analyses were used to determine direct and indirect factors that may contribute to feelings of hopelessness. Path analyses were used to assess the underlying structure of hopelessness. All analyses were conducted by gender.

Results: Almost half the participants reported moderate to severe hopelessness. There were no differences in frequency of feeling hopeless or level of hopelessness by gender or sexual orientation. Dissatisfaction with finances, dissatisfaction with physical health, and low HIV-related emotional support were found to be directly associated with hopelessness for both women and men. Although having some indirect factors in common, unemployment and HIV stigmatization, women and men had different underlying structures of hopelessness.
\end{abstract}

Conclusions: Our findings are important to HIV clinicians in identifying those at risk of hopelessness from a gender perspective in order to reduce preventable psychological distress among people living with HIV.

Keywords: Hopelessness, People living with HIV, Contributors, Gender differences, Sweden

\section{Background}

The majority of people living with HIV in the West are on antiretroviral therapy (ART) achieving and maintaining undetectable viral loads and therefore have close to normal life expectancy and are not at risk of transmitting HIV to HIV-negative sex partners. Yet, many people living with HIV are confronted with HIV-related medical, psychosocial, sexual, and existential stressors. A high

*Correspondence: lena.nilsson.schonnesson@ki.se

${ }^{8}$ Kolstan, Övre Kolstan, 67198 Gunnarskog, Sweden

Full list of author information is available at the end of the article level of physical and psychosocial stressors can lead to a number of psychological outcomes, including feelings of hopelessness [1-3]. Numerous studies have examined the prevalence of and the factors associated with hopelessness in patients with various chronic diseases including cancer [4-6]. Yet, there has been relatively little research of hopelessness in people living with HIV.

According to the Diagnostic and Statistical Manual of Mental Disorders, 5th edition [DSM-5]; [7], hopelessness is a symptom of depressive disorders. However, hopelessness may occur independent of depression [4], or as a precursor to a subtype of depression called hopelessness 
depression [8]. Several studies have shown a person can have feelings of hopelessness without feeling depressed [4].

Hopelessness, triggered by intrapsychic crisis and/ or external stressors [9], is indicated by expectations of negative outcomes and feelings of helplessness to change those expectations [8]. Beck et al. [10] described three dimensions of hopelessness: negative future expectations (the cognitive dimension), negative feelings about the future (the affective dimension), and negative thoughts and feelings about one's ability to change or improve the future (the motivational dimension).

A number of factors have been found to be associated with feelings of hopelessness. Demographic characteristics include being female, single, or Afro-American. Low income or lack of HIV-related emotional support are associated, as is poor physical functioning, side-effects from ART, and poorer ART adherence. Hopelessness has also been found to be associated with internalized HIV stigmatization or psychological symptoms associated with a recent HIV diagnosis [11-16].

Hopelessness in people living with HIV is a significant area of study, as it can negatively affect sexual satisfaction [17], quality of life [15], and life satisfaction [14]. A Swedish study among people living with HIV found hopelessness was the principal predictor of quality of life [18]. The aim of the present study was to assess prevalence and levels of hopelessness and its direct and indirect contributors in people living with HIV in Sweden. Accumulated research evidence has recognized gender differences in the general population regarding psychosocial and life situation variables [19-21]. Thus, we decided to examine women and men separately as only statistically controlling for gender is unable to allow specific focus on such differences [22]. Most studies investigating hopelessness among people living with HIV have used exclusively male samples. The few studies that have included women and men in their samples did not examine gender specific correlates or had limited discussion about the impact of gender on feelings of hopelessness.

\section{Methods}

\section{Participants and procedure}

This study utilized data from a large nation-wide, crosssectional study "Living with HIV infection in Sweden" examining quality of life and its correlates through an anonymous self-reported questionnaire executed between December 2013 and August 2014. The questionnaire including 77 items translated into ten languages. It was pilot tested in collaboration with Swedish nongovernmental HIV organizations. All study procedures were approved by the Regional Ethical Board, Stockholm (DNR 2013/1552-31/4).
Participants were enrolled in the study from 15 infectious disease outpatient clinics across Sweden and two needle and syringe exchange clinics in Stockholm. These 17 clinics account for $75 \%$ of the HIV care provided in Sweden. Patients in the clinics were eligible to participate if they were 18 years old and had been diagnosed with HIV for at least six months.

All consecutive outpatients visiting their HIV unit were informed about the study and invited to participate in the study. Altogether, 1096 women and men completed the questionnaire. The response rate was about one quarter of these who could have attended the 17 HIV units at the time of data collection. No incentive was given. Recruitment and data collection procedures are described in further detail elsewhere $[17,18]$.

The present study analyzed data from 967 participants (89\%) who had complete data on the Beck Hopelessness Scale.

\section{Measures}

Hopelessness was measured using the Beck Hopelessness Scale [10]. The structure of the Beck' Hopelessness Scale has been validated in Sweden on a clinical sample [23]. The scale is designed to measure the cognitive, affective, and motivational dimensions of hopelessness during the last seven days. The scale is a 20 -item, self-administered questionnaire. All items are scored on a true-false rating scale. After recoding negatively worded items, the number of endorsed items is combined to a sum-score; the higher scores the greater hopelessness levels. The participants were classified into: no hopelessness (scores $0-3$ ), mild hopelessness (scores 4-8), moderate hopelessness (scores 9-14) and severe hopelessness (scores 15-20) [10]. Cronbach's $\alpha$ in this sample was very good, 0.91 (mean scale score 5.44, median 4.00, SD 5.14).

In addition to hopelessness, we asked participants to describe their sociodemographic characteristicsincluding gender, sexual orientation, relationship status, birth country, education, and employment status. Satisfaction with their financial situation was measured by a statement derived from the Life Satisfaction Scale [24]. We also measured clinical and psychosocial factors. Clinical factors included time since HIV diagnosis (0 to 10 years/more than 10 years), bothersome physical ART side-effects (yes/no), impact of ART on daily living (low/ high), and satisfaction with physical health (satisfied/dissatisfied) [24].

We also assessed several psychosocial factors. HIVrelated trauma symptoms were measured using the Impact Event Scale [25]. Based on the distribution, scale scores were dichotomized to subclinical $(\leq 8)$ and symptoms present (9-75). HIV-related stigmatization was measured using a short version of the HIV Stigma Scale 
[26, 27], including three subscales: internalized, anticipated, and personalized stigma. Scores on the three subscales dichotomized to reflect low stigma (3-7) and high stigma (8-12). The impact of HIV on one's life was measured by three subscales indicating no impact, HIV negative impact, and HIV positive impact. HIV-related emotional support from partners, family members or friends was dichotomized into high/low. Satisfaction with HIV openness was assessed by a single item having three choices (yes, no, would like to be more open, no, would like to be less open). Impact of the HIV diagnosis on self-image and meaningfulness of life were measured by single items having three choices (weakened, no impact, reinforced).

\section{Statistical analyses}

In total, 1096 eligible individuals responded to the anonymous questionnaire of whom 762 were men, 320 were women, four participants reported "other"gender identity, and ten participants did not report their gender. Fourteen participants (4 "other" and 10 missing) were dropped from further analysis, leaving a total of 1082 study participants.

If scores were missing for one or two hopelessness scale items, the missing score was replaced with a participant's mean scale score. If more than two scale items had missing values, data were excluded from further analyses. The vast majority $(89 \%, n=967)$ had complete data on the Beck Hopelessness Scale. After examining responses to the hopelessness scale, we found it to be highly skewed toward lower scores. Therefore, hopelessness was recoded as a binary variable (no feelings of hopelessness (scores 0-3) or feeling hopeless (scores 4-20).

Analyses were conducted separately for women and men in three steps using MPlus version 7.4. To determine which factors were associated with hopelessness, binary logistic regression for sociodemographic characteristics and HIV related clinical and psychosocial measures were calculated. Factors with a statistically significant association with hopelessness were included in a multiple logistic regression model.

Secondly, to establish factors which might indirectly affect hopelessness, binary logistic regressions were conducted between sociodemographic characteristic, HIV related clinical, and psychosocial factors and those factors that were identified as statistically directly associated with hopelessness. Statistically significant variables were then included in multiple logistic regression models. The results of steps one and two provided possible models, one for women and one for men, of hopelessness.

The final analytical step evaluated the fit of the direct and indirect contributors of hopelessness. Separate path models were developed for women and men including only the statistically significant variables from previous analyses using maximum likelihood estimators. Full models were compared to models including all potential predictors using the likelihood difference test, where -2 times the log-likelihood difference is distributed as chisquare [28] and differences in Akaike Information Criteria (AIC) and Bayesian Information Criteria (BIC).

To manage different degrees of missing data, multiple imputation followed by maximum likelihood estimation was being used [29]. Imputation for variables with missing values was conducted using Bayesian analyses [30]. Ten imputed datasets were used in the estimation of all analyses using maximum likelihood estimation. Maximum likelihood parameter estimates for each analysis were averaged over the set of 10 analyses, and standard errors were computed using the average of the standard errors of the analyses and the between analyses parameter estimation.

\section{Results}

Women were younger than men. The average age of women was 43 . The average age of men was just shy of 50 . Two-thirds of men were native Swedish, while two-thirds of women were born outside Sweden. More than half of men and almost two-thirds of women were in an intimate relationship at the time of data collection. Two thirds of men said they were non-heterosexual, while almost all women said they were heterosexual. Nearly half of men and just over $40 \%$ of women had at least some post-high school education. Most men and women were working. Roughly equal percentages of men had been diagnosed with HIV for less than or more than ten years. Differences in time since HIV diagnosis was somewhat greater in women, with the majority have been diagnosed for less than 10 years (Table 1 ).

Feelings of hopelessness were reported by almost half of study participants. Of these, about half reported feeling mild hopelessness, a quarter moderate hopelessness, and another quarter severe hopelessness. There were no differences in frequency of feeling hopeless or level of hopelessness by gender or sexual orientation.

\section{Binary and multiple logistic regression analyses predicting hopelessness}

The binary logistic regression analyses of factors associated with hopelessness showed dissatisfaction with finances and physical health, and HIV-related emotional support were associated for both women and men (Table 2). For men, but not women, age and being single were associated with hopelessness. The statistically significant binary variables remained significant in the multiple logistic regression models for both genders. 
Table 1 Sociodemographic characteristics of study participants $(n=967)$

\begin{tabular}{|c|c|c|}
\hline Variable & $\begin{array}{l}\text { Men }(n=699)(\%) / \\
\text { mean (SD) }\end{array}$ & $\begin{array}{l}\text { Women } \\
(n=268)(\%) / \\
\text { mean (SD) }\end{array}$ \\
\hline Age (years) & $49.8(11.7)$ & $42.7(10 ., 4)$ \\
\hline \multicolumn{3}{|l|}{ Sexual orientation } \\
\hline Heterosexual & $226(34.3)$ & $194(94.6)$ \\
\hline Non-heterosexual & $433(65.7)$ & $11(5.4)$ \\
\hline \multicolumn{3}{|l|}{ Country of birth } \\
\hline Sweden & $477(69.3)$ & $83(31.4)$ \\
\hline Outside Sweden & $211(30.7)$ & $181(68.6)$ \\
\hline \multicolumn{3}{|l|}{ Current relationship status } \\
\hline In an intimate relationship & $389(55.8)$ & $171(64.8)$ \\
\hline Single & $308(44.2)$ & $93(32.5)$ \\
\hline \multicolumn{3}{|l|}{ Years of school } \\
\hline$\leq 12$ years & $348(50.8)$ & $156(58.9)$ \\
\hline$\geq 13$ years & $337(49.2)$ & $109(41.1)$ \\
\hline \multicolumn{3}{|l|}{ Employment } \\
\hline Working & $478(77.0)$ & $178(70.9)$ \\
\hline Non-working & $143(23.0)$ & $73(29.1)$ \\
\hline \multicolumn{3}{|l|}{ Time since HIV diagnosis } \\
\hline$<1-10$ years & $335(48.7)$ & $142(54.6)$ \\
\hline$>10$ years & $353(51.3)$ & $118(45.4)$ \\
\hline
\end{tabular}

Factors found to be significantly related to hopelessness in women and men were used as dependent variables to assess which factors might be indirectly associated with hopelessness. As shown in Table 3, lower education and being unemployed were associated with dissatisfaction with finances for women. Lower education, unemployed, and anticipated stigmatization were associated with dissatisfaction with physical health. Finally, being single and experiencing bothersome ART side effects were associated with low HIV-related emotional support.

The results for men are shown in Table 4. Being born outside Sweden, unemployed, and time since HIV diagnosis associated with age, being single, dissatisfaction with finances, and dissatisfaction with physical health. Internalized stigmatization and dissatisfaction with openness about HIV were found to be associated with low HIV-related emotional support.

\section{Path models}

The binary and multiple analyses suggested hopelessness path models that could be tested. The path models for women and men are show in Figs. 1 and 2. Both models showed good fit. All factors found to have a significant association with hopelessness or as an indirect factor remained significant in path models.
Results showed dissatisfaction with physical health had the strongest direct path to hopelessness in women. Dissatisfaction with finances and low HIVrelated emotional support were also found to be significant and equally strong. In men, the same paths were found to be significant, but with different strengths than in the women's model. The strongest path was dissatisfaction with finances, followed by dissatisfaction with physical health and low HIV-related emotional support. Being single was the fourth strongest path, followed by age.

Indirect paths to hopelessness were quite different for women and men. Among women, paths from low education and unemployed were found to dissatisfaction with finances and physical health. The only significant indirect path from anticipated stigmatization was found to dissatisfaction with physical health. The path from being single to low HIV-related emotional support was found to be strong, while the path from bothersome ART sides effects to low HIV-related emotional support was significant but weak.

For men, the model showed several paths from being unemployed. The strongest path was from unemployment to dissatisfaction with finances. Other paths from unemployment were to age, being single, and dissatisfaction with physical health. Two paths were significant from born outside Sweden. The strongest was to age followed by dissatisfaction with finances. Two paths were also found to be significant from time since HIV diagnosis. The path from time since HIV diagnosis to age was found to be very strong. The path from time since HIV diagnosis to dissatisfaction with finances was weak. Only one path was found to be significant from internalized stigmatization and dissatisfaction with openness about HIV. Both paths ran from these variables to low HIVrelated emotional support.

\section{Discussion}

The aim of this study was to assess prevalence and levels of hopelessness and its underlying structure in a sample of women and men living with HIV in Sweden. We found feelings of moderate to severe hopelessness in about half of both women and men, which is much higher than in studies involving general populations [10,31]. This suggests feelings of hopeless are relatively common in people living with HIV, and may indicate, as some have suggested, an elevated risk of suicidal ideation [2, 32, 33]. As at least one other study, we found no differences in prevalence or level of hopelessness between women and men [2].

Nevertheless, we found different underlying structures of hopelessness in women and men, although the path models for each did share common factors contributing 
Table 2 Binary and multiple logistic regressions predicting hopelessness among male $(n=699)$ and female $(n=268)$ study participants

\begin{tabular}{|c|c|c|c|c|}
\hline \multirow[t]{2}{*}{ Variable } & \multicolumn{2}{|c|}{ Binary logistic regression } & \multicolumn{2}{|c|}{ Multiple logistic regression } \\
\hline & $\begin{array}{l}\text { Male participants OR } \\
(95 \% \mathrm{Cl})\end{array}$ & $\begin{array}{l}\text { Female participants OR } \\
(95 \% \mathrm{Cl})\end{array}$ & $\begin{array}{l}\text { Male participants aOR } \\
(95 \% \mathrm{Cl})\end{array}$ & $\begin{array}{l}\text { Female } \\
\text { participants aOR } \\
(95 \% \mathrm{Cl})\end{array}$ \\
\hline \multicolumn{5}{|l|}{ Sociodemographic characteristics } \\
\hline Age & $1.02^{* *}(1.00,1.03)$ & $1.00(0.96,1.03)$ & $1.02^{* *}(1.01,1.04)$ & \\
\hline \multicolumn{5}{|l|}{ Country of birth } \\
\hline Sweden & 1 & 1 & & \\
\hline Outside Sweden & $1.34(0.89,2.02)$ & $1.38(0.76,2.54)$ & & \\
\hline \multicolumn{5}{|l|}{ Relationship status } \\
\hline In an intimate relationship & 1 & 1 & 1 & \\
\hline Single & $1.48^{*}(1.04,2.10)$ & $1.69(0.88,3.24)$ & $1.55^{*}(1.09,2.20)$ & \\
\hline \multicolumn{5}{|l|}{ Sexual orientation } \\
\hline Heterosexual & 1 & 1 & & \\
\hline Non-heterosexual & $1.11(0.72,1.69)$ & $1.90(0.39,9.24)$ & & \\
\hline \multicolumn{5}{|l|}{ Years of school } \\
\hline$\leq 12$ years & $1.14(0.79,1.63)$ & $1.44(0.82,2.53)$ & & \\
\hline$\geq 13$ years & 1 & 1 & & \\
\hline \multicolumn{5}{|l|}{ Employment } \\
\hline Working & 1 & 1 & & \\
\hline Non-working & $1.52(0.90,2.57)$ & $1.33(0.75,2.37)$ & & \\
\hline \multicolumn{5}{|l|}{ Financial satisfaction } \\
\hline Satisfied & 1 & 1 & 1 & 1 \\
\hline Dissatisfied & $3.33^{* * *}(2.15,5.16)$ & $2.25^{* *}(1.25,4.07)$ & $3.87^{* * *}(2.59,5.80)$ & $2.29^{* *}(1.26,4.14)$ \\
\hline \multicolumn{5}{|l|}{ Self-reported HIV clinical factors } \\
\hline \multicolumn{5}{|l|}{ Time since HIV diagnosis } \\
\hline$\leq 10$ years & 1 & 1 & & \\
\hline$>10$ years & $0.97(0.66,1.41)$ & $1.24(0.64,2.39)$ & & \\
\hline \multicolumn{5}{|c|}{ Experiencing bothersome physical ART side-effects } \\
\hline Yes & $1.43(0.96,2.13)$ & $1.72(0.86,3.44)$ & & \\
\hline No & 1 & 1 & & \\
\hline \multicolumn{5}{|l|}{ Impact of ART on daily living } \\
\hline High & $1.03(0.71,1.51)$ & $0.81(0.44,1.50)$ & & \\
\hline Low & 1 & 1 & & \\
\hline \multicolumn{5}{|l|}{ Physical health satisfaction } \\
\hline Satisfied & 1 & 1 & 1 & 1 \\
\hline Dissatisfied & $2.56^{* * *}(1.69,3.88)$ & $3.32 * * *(1.76,6.27)$ & $2.70^{* * *}(1.80,4.06)$ & $3.56^{* * *}(1.87,6.81)$ \\
\hline \multicolumn{5}{|l|}{ Psychosocial factors } \\
\hline \multicolumn{5}{|l|}{ HIV-related trauma symptoms } \\
\hline Subclinical & 1 & 1 & & \\
\hline Symptoms present & $1.31(0.89,1.91)$ & $0.87(0.46,1.62)$ & & \\
\hline \multicolumn{5}{|l|}{ Internalized stigmatization } \\
\hline Low & 1 & 1 & & \\
\hline High & $0.90(0.63,1.31)$ & $0.71(0.43,1.18)$ & & \\
\hline \multicolumn{5}{|l|}{ Anticipated stigmatization } \\
\hline Low & 1 & 1 & & \\
\hline High & $1.30(0.88,1.92)$ & $1.05(0.55,2.03)$ & & \\
\hline \multicolumn{5}{|l|}{ Personalized stigmatization } \\
\hline Low & 1 & 1 & & \\
\hline High & & $0.89(0.42,1.87)$ & & \\
\hline
\end{tabular}


Table 2 (continued)

\begin{tabular}{|c|c|c|c|c|}
\hline \multirow[t]{2}{*}{ Variable } & \multicolumn{2}{|c|}{ Binary logistic regression } & \multicolumn{2}{|c|}{ Multiple logistic regression } \\
\hline & $\begin{array}{l}\text { Male participants OR } \\
(95 \% \mathrm{Cl})\end{array}$ & $\begin{array}{l}\text { Female participants OR } \\
(95 \% \mathrm{CI})\end{array}$ & $\begin{array}{l}\text { Male participants aOR } \\
(95 \% \mathrm{CI})\end{array}$ & $\begin{array}{l}\text { Female } \\
\text { participants aOR } \\
(95 \% \mathrm{Cl})\end{array}$ \\
\hline \multicolumn{5}{|l|}{ Impact of HIV on one's life } \\
\hline No impact & $0.92(0.73,1.16)$ & $1.05(0.71,1.56)$ & & \\
\hline Negative impact & $0.92(0.74,1.15)$ & $0.99(0.69,1.40)$ & & \\
\hline Positive impact & $0.91(0.73,1.15)$ & $0.98(0.69,1.40)$ & & \\
\hline \multicolumn{5}{|l|}{ HIV-related emotional social support } \\
\hline High & 1 & 1 & 1 & 1 \\
\hline Low & $2.43^{* * *}(1.58,3.74)$ & $2.59^{* *}(1.33,5.04)$ & $2.49^{* * *}(1.70,3.66)$ & $2.56^{* *}(1.30,5.04)$ \\
\hline Satisfaction with openness about HIV & $0.99(0.74,1.33)$ & $1.44(0.91,2.29$ & & \\
\hline Change in sense of self-esteem & $0.98(0.77,1.24)$ & $0.74(0.48,1.13)$ & & \\
\hline Change in sense of meaningfulness of life & $1.00(0.76,1.30)$ & $1.41(0.88,2.24)$ & & \\
\hline
\end{tabular}

$O R$ odds ratio, $a O R$ adjusted odds ratio, $C l$ confidence interval, $A R T$ antiretroviral therapy

${ }^{*} \mathrm{p}<0.05 ;{ }^{* *} \mathrm{p}<0.01 ;{ }^{* * *} \mathrm{p}<0.001$

Table 3 Predictors of mediating variables of hopelessness, female study participants $(n=268)$

\begin{tabular}{|c|c|c|c|}
\hline & $\begin{array}{l}\text { Financial dissatisfaction aOR } \\
(95 \% \mathrm{Cl})\end{array}$ & $\begin{array}{l}\text { Physical health dissatisfaction aOR } \\
(95 \% \mathrm{Cl})\end{array}$ & $\begin{array}{l}\text { Low HIV-related } \\
\text { emotional support aOR } \\
(95 \% \mathrm{Cl})\end{array}$ \\
\hline \multicolumn{4}{|l|}{ Sociodemographic characteristics } \\
\hline Age & $0.98(0.95,1.00)$ & & \\
\hline \multicolumn{4}{|l|}{ Relationship status } \\
\hline In an intimate relationship & & 1 & 1 \\
\hline Single & & $1.55(0.87,2.76)$ & $3.28^{* * *}(1.72,6.25)$ \\
\hline \multicolumn{4}{|l|}{ Years of school } \\
\hline$\leq 12$ years & $1.92^{*}(1.10,3.35)$ & $2.75^{* *}(1.49,5.10)$ & \\
\hline$\geq 13$ years & 1 & 1 & \\
\hline \multicolumn{4}{|l|}{ Employment } \\
\hline Working & 1 & 1 & \\
\hline Non-working & $3.48^{* * *}(1.85,6.52)$ & $2.51^{* *}(1.33,4.71)$ & \\
\hline \multicolumn{4}{|l|}{ Self-reported HIV clinical factors } \\
\hline \multicolumn{4}{|l|}{ Time since HIV diagnosis } \\
\hline$\leq 10$ years & & 1 & \\
\hline$\geq 10$ years & & $1.33(0.76,2.35)$ & \\
\hline \multicolumn{4}{|c|}{ Experiencing bothersome physical ART side-effects } \\
\hline Yes & & & $0.44^{*}(0.22,0.89)$ \\
\hline No & & & 1 \\
\hline \multicolumn{4}{|l|}{ Psychosocial factors } \\
\hline \multicolumn{4}{|l|}{ Anticipated stigmatization } \\
\hline Low & & & 1 \\
\hline High & & & $1.89^{*}(1.05,3.41)$ \\
\hline
\end{tabular}

$a O R$ adjusted odds ratio, $C l$ confidence interval, $A R T$ antiretroviral therapy

${ }^{*} \mathrm{p}<0.05 ;{ }^{* *} \mathrm{p}<0.01 ;{ }^{* * *} \mathrm{p}<0.001$

directly to hopelessness, that is dissatisfaction with one's physical health, dissatisfaction with one's finances, and low HIV-related emotional support.
Being dissatisfied with one's physical health was a strong predictor of hopelessness. This suggests predictors of feelings of hopelessness are related to the effect 
Table 4 Predictors of mediating variables of hopelessness, male study participants $(n=699)$

\begin{tabular}{|c|c|c|c|c|c|}
\hline & Age aOR $(95 \% \mathrm{Cl})$ & $\begin{array}{l}\text { Being single aOR }(95 \% \\
\text { Cl) }\end{array}$ & $\begin{array}{l}\text { Financial } \\
\text { dissatisfaction } \\
\text { aOR }(95 \% \mathrm{Cl})\end{array}$ & $\begin{array}{l}\text { Physical health } \\
\text { dissatisfaction aOR } \\
(95 \% \mathrm{Cl})\end{array}$ & $\begin{array}{l}\text { Low HIV-related } \\
\text { emotional support aOR } \\
(95 \% \mathrm{Cl})\end{array}$ \\
\hline \multicolumn{6}{|c|}{ Sociodemographic characteristics } \\
\hline \multicolumn{6}{|c|}{ Country of birth } \\
\hline Sweden & 1 & & 1 & & \\
\hline Outside Sweden & $-4.76^{* * *}(-6.50,-3.02)$ & & $2.41^{* * *}(1.66,3.61)$ & & \\
\hline \multicolumn{6}{|c|}{ Years of school } \\
\hline$\leq 12$ years & & $0.75(0.55,1.03)$ & $1.43(0.98,2.07)$ & & \\
\hline$\geq 13$ years & & 1 & 1 & & \\
\hline \multicolumn{6}{|l|}{ Employment } \\
\hline Working & 1 & 1 & 1 & 1 & \\
\hline Non-working & $5.00^{* * *}(2.67,7.34)$ & $1.77^{* *}(1.22,2.71)$ & $7.21 * * *(4.54,11.45)$ & $2.48^{* * *}(1.64,3.76)$ & \\
\hline \multicolumn{6}{|c|}{ Self-reported HIV clinical factors } \\
\hline \multicolumn{6}{|c|}{ Time since HIV diagnosis } \\
\hline$\leq 10$ years & 1 & & 1 & & \\
\hline$\geq 10$ years & $7.58^{* * *}(5.96,9.21)$ & & $0.63^{*}(0.43,0.93)$ & & \\
\hline \multicolumn{6}{|c|}{ Experiencing bothersome physical ART side-effects } \\
\hline Yes & & & & $1.41(0.94,2.12)$ & $1.74(0.98,2.66)$ \\
\hline No & & & & 1 & 1 \\
\hline \multicolumn{6}{|l|}{ Psychosocial factors } \\
\hline \multicolumn{6}{|c|}{ Internalized stigmatization } \\
\hline Low & & & & & 1 \\
\hline High & & & & & $0.60^{*}(0.42,0.87)$ \\
\hline \multicolumn{6}{|c|}{ Anticipated stigmatization } \\
\hline Low & & & 1 & 1 & \\
\hline High & & & $0.70(0.47,1.04)$ & $0.82(0.58,1.15)$ & \\
\hline \multicolumn{6}{|c|}{ Personalized stigmatization } \\
\hline Low & & & 1 & & \\
\hline High & & & $1.42(0.92,2.18)$ & & \\
\hline $\begin{array}{l}\text { Satisfaction with } \\
\text { openness about } \\
\text { HIV }\end{array}$ & & & & & $0.72^{*}(0.55,0.94)$ \\
\hline
\end{tabular}

$a O R$ adjusted odds ratio, $\mathrm{Cl}$ confidence interval, $A R T$ antiretroviral therapy

${ }^{*} \mathrm{p}<0.05 ;{ }^{* *} \mathrm{p}<0.01 ;{ }^{* * *} \mathrm{p}<0.001$

HIV is having on the body and demonstrates a strong connection between the physical and psychological [16]. Such a relationship is also found in the area of other chronic conditions such as cardiovascular diseases, cancer, and diabetes [34].

Dissatisfaction with one's physical health was the strongest predictor of hopelessness in women, but not men, suggesting women may feel negative health outcomes somewhat more strongly.

Dissatisfaction with finances suggests financial hardship is strongly associated with feelings of hopelessness. Whether this is related to feelings of lower socio-economic status or difficulties to independently provide for one's self is unclear [14, 35]. For men, dissatisfaction with finances presented the strongest pathway and, as suggested by the model, is strongly related to unemployment.

Low HIV-related emotional support was almost an equally strong predictor of hopelessness for both men and women. It may be a consequence of concealing one's HIV status out of fear of stigmatization and rejection or the experience of other's withdrawal upon HIV disclosure. This finding strongly indicates having an emotional social support system is important for maintaining psychological wellbeing in people living with $\operatorname{HIV}[8,11$, 15]. The significance of emotional social support is a well-known fact also in other chronic [36] and acute [37] health condition as well as in the general population [38]. 

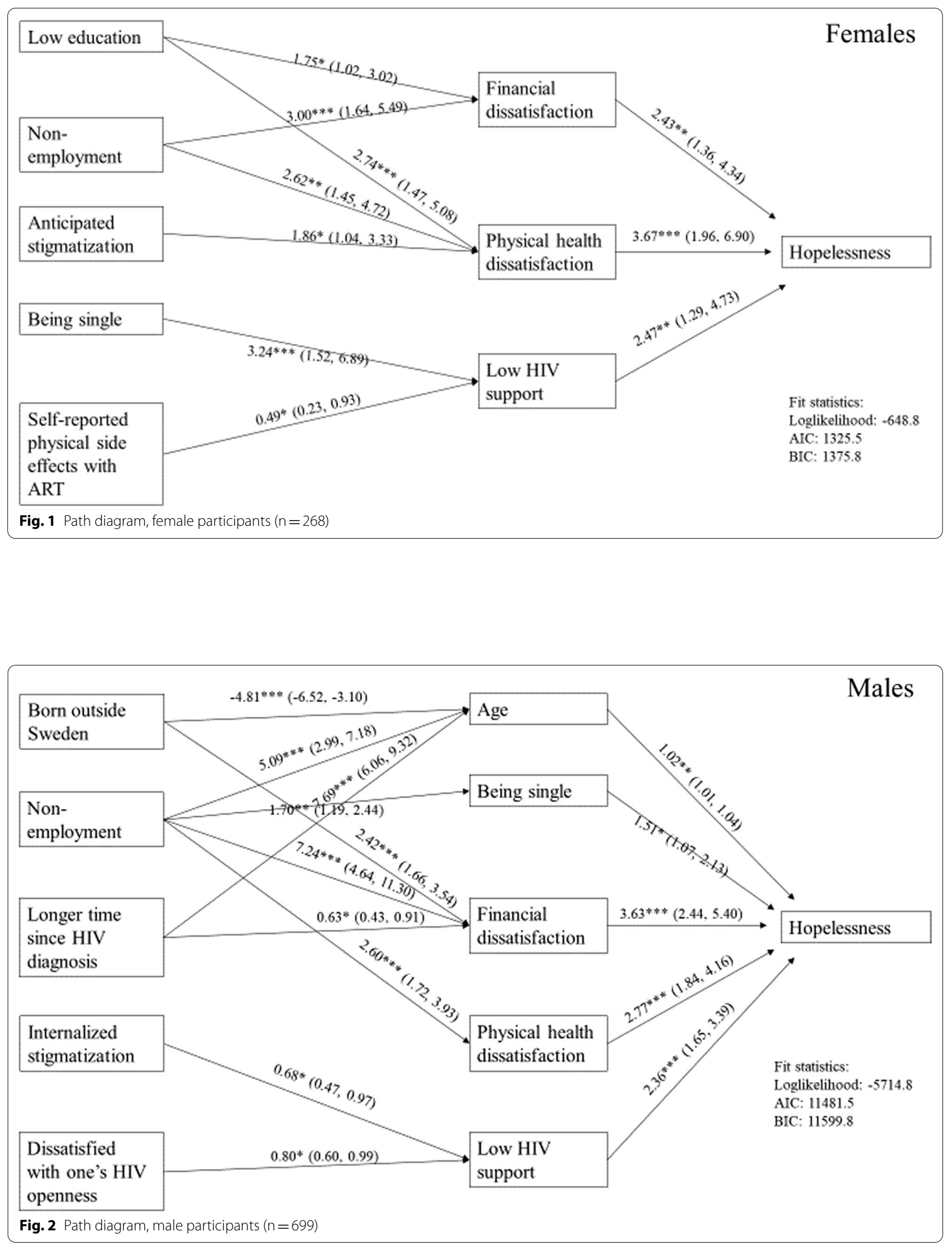
Being single and increasing age predicted hopelessness in men, but not women. The paths from these two predictors to hopelessness were not strong, especially the path from age. The association between being single and feelings of hopeless in men has been observed by at least one other study [14]. We do not know whether being single was HIV-related or of a circumstantial or intentional character. There may be a longing for an intimate relationship, but HIV puts up barriers to fulfill this wish [17]. As intimate relationship functions as a protective shield in stressful times, being single may trigger feelings of loneliness. Research acknowledges loneliness as a central aspect of life among people living with HIV [39], but also for people with cardiovascular, cerebrovascular, and other chronic diseases [40]. The association between loneliness and depression is well documented [39-41].

Increasing age has a number of possible explanations. Adverse psychological effects of HIV as well as potential chronic health problems may be common among older people with HIV [42]. Increasing age may also be indicative of increased feelings of vulnerability to social isolation, existential issues such as meaning of life [43], existential isolation [44], and feelings associated with dying and death.

Women presented a comparatively simpler underlying structure of hopelessness than men, in that fewer paths were found to significantly influence feelings of hopeless through direct factors. Men had a more complex structure, but this was due largely to employment status. For both women and men, the strongest indirect path was from unemployment to dissatisfaction with finances, strongly suggesting unemployment indirectly has a significant impact on psychological wellbeing [35, 45-47]. Whether unemployment is to lack of a job, longterm sick leave, disability pension, or pension is unclear from the data. Even so, unemployment is likely indicative of economic strain, discontent with circumstances, and possibly feeling decreased social status associated with not being a "working person" [48]. It is also possible unemployment may associate with physical limitations due to HIV [47].

While HIV stigmatization was indirectly associated with hopelessness for both women and men, type of stigmatization and its indirect paths differed by gender. Among women, anticipated stigmatization, which may be perceived as a stressor, had an indirect effect on hopelessness through dissatisfaction with physical health. Our data supports other studies that anticipated stigmatization undermines the physical and mental well-being $[49,50]$. For men, internalized HIV stigmatization indirectly affected hopelessness, similar to another study [12]. Characteristics of internalized HIV stigmatization are among others self-loathing and feelings of being inferior to others. These may be strong barriers to HIV disclosure reflected in low HIV-related emotional support, leading to social isolation and loneliness. Other than having unemployment and HIV stigmatization in common, the factors indirectly associated with hopelessness were different in men and women.

For women, there were three indirect paths to hopelessness: being single, lower education, and physical side effects from ART. The strongest indirect path was from being single to low HIV-related emotional support, which is somewhat difficult to understand, as there may be several possible explanations. But, irrespective of its underlying cause, low emotional support may lead to feelings of being excluded and increased vulnerability to social isolation, loneliness and increased psychological distress. Lower level of education had a strong indirect path to physical health dissatisfaction, suggesting lower education indirectly has a significant negative impact on psychological wellbeing [51]. There was also an indirect path from lower level of education to financial dissatisfaction. Less education may be a surrogate measure for lower socio-economic status $[35,51]$. Self-reported physical side effects from ART had through low HIV-related emotional support an indirect, but weak effect on hopelessness. Other studies have observed direct association between physical side effects and hopelessness $[13,16]$.

For men, three factors were indirectly associated with feelings of hopeless: born outside Sweden, time since HIV diagnosis, and dissatisfaction with one's openness about HIV. There were two indirect paths from born outside Sweden to hopelessness. The strongest was to age, suggesting foreign born men may have been younger than Swedish born men living with HIV. This is supported by the Swedish HIV statistics [52]. The other indirect path from born outside Sweden was to dissatisfaction with finances. Migrants in Sweden are often economically more vulnerable than Swedish-born citizens [53]. Their financial hardship may be indicative of the combination of migration and HIV status, suggesting being a migrant indirectly increases psychological distress $[49,53,54]$. In contrast to Stanley et al.s study [14], time with diagnosed HIV infection had a strong indirect effect on hopelessness through age. Older men were likely to have been diagnosed with HIV infection for more than 10 years, signifying they may have ongoing health problems or disability related to HIV infection [55]. The indirect path from time since HIV diagnosis to financial dissatisfaction was weak, but may reflect increased time living with HIV has had its toll on the financial situation. Dissatisfaction with one's openness about HIV had a weak association through low HIV-related emotional support to feelings of hopelessness. 


\section{Strengths and limitations}

The strength of this study is its nationwide, multicultural sample, including almost a quarter of these who could have attended the 17 HIV units in Sweden at the time of data collection. Nevertheless, given the cross-sectional design, cause and effect relationships are not possible. Furthermore, underlying structures of hopelessness may change over time given that feelings of hopelessness are dynamic. Another limitation is response bias. We don't know about the people who didn't enroll, and why not. Or what proportion didn't visit a clinic in that time frame. This study also contained a smaller proportion of women ( $28 \%$ vs. $38 \%$ overall) and a higher proportion of Swedish born participants ( $59 \%$ vs. $36 \%$ overall) than the national demographic of people living with HIV. These differences may decrease the generalizability of the findings to the HIV population in Sweden. Considering the average age of the participants were higher in men ( 43 for women and approximately 50 for men) the question remains if a younger study population would have yielded different results. Nevertheless, the average age of women and men in our sample corresponds with the age distribution of the larger population of people living with HIV in Sweden at the time of data collection. Because the sample was drawn only from persons living with HIV in Sweden, results are not generalizable to populations living elsewhere. As the data were self-reported, they may include the social desirability bias, which may have decreased given the anonymous questionnaire. We did not measure depression and it is possible that it would co-vary with feelings of hopelessness. Further studies are needed to assess their associations and underlying structures.

\section{Conclusions}

Our study adds to the limited research on hopelessness and its correlates among people living with HIV by examining direct and indirect correlates of hopelessness by gender. Despite successful antiretroviral treatment, the study shows that people living with HIV in Sweden experience high levels of hopelessness. Our findings indicate few gender differences in direct contributors to hopelessness, but different path models of indirect factors. In contrast to research on corelates of depression, we did not find any significant associations between gender, younger age, post-traumatic stress, HIV stress and hopelessness [56]. This suggests feelings of hopelessness deserve to be studied independently of depression and more studies are warranted.

Our study clearly signifies that HIV is not a normal, chronic disease like any other, but a psychosocial condition and not just a medical one [57]. Our findings are important to HIV clinicians in identifying those at risk of hopelessness from a gender perspective in order to reduce preventable psychological distress among people living with HIV.

\begin{abstract}
Acknowledgements
We gratefully acknowledge all of the people living with HIV who volunteered to participate in this study and the assisting staff at each participating infectious disease outpatient clinics and needle and syringe exchange clinics. This study was funded by The Public Health Agency of Sweden to professor AnnaMia Ekström (principal investigator).
\end{abstract}

\section{Authors' contributions}

$L N S, M R, L E, G A$, and AME contributed to the study conception and design. Material preparation and data analysis were performed by LNS and DGH. The manuscript was written by LNS and all authors contributed to editing of this manuscript. All authors read and approved the final manuscript.

\section{Funding}

Open access funding provided by Karolinska Institute. This study was funded by The Public Health Agency of Sweden to professor Anna- Mia Ekström (principal investigator). No role of funder.

\section{Availability of data and materials}

The data underlying the findings in our study are not publicly available because the original approval by the Regional Ethical Board, Stockholm, Sweden. (DNR 2013/1552-31/4) and the informed consent from the subjects participating in the study did not include such a direct, free access.

\section{Declarations}

Ethics approval and consent to participate

The study was conducted in compliance with the ethical standards of the Central Ethical Review Board, Sweden, governing protection of human subjects and adhered to the Declaration of Helsinki. It was reviewed and approved by the Regional Ethical Board, Stockholm, Sweden. (DNR 2013/155231/4). Informed consent was obtained from all individual participants included in the study.

\section{Consent for publication}

Not applicable.

\section{Competing interests}

The authors declare that they have no competing interests.

\section{Author details}

1'Department of Global Public Health, Karolinska Institutet, 17177 Stockholm, Sweden. ${ }^{2}$ Joycelyn Elders Professor and Chair of Sexual Health Education, Department of Family Medicine, University of Minnesota Medical School, Minneapolis, MN, USA. ${ }^{3}$ Departamento de Medicina Familiar, Escuela de Medicina, Pontificia Universidad Catolica de Chile, Santiago, Chile. ${ }^{4}$ Department of Neurobiology, Care Sciences and Society, Karolinska Institutet, SE-141 83 Huddinge, Sweden. ${ }^{5}$ School of Health Sciences, City, University of London, London EC1V OHB, UK. ${ }^{6}$ Medical Unit Infectious Diseases, Karolinska University Hospital, 14186 Stockholm, Sweden. ${ }^{7}$ Joycelyn Elders Professor and Dean, Fay W. Boozman College of Public Health, University of Arkansas for Medical Sciences, Little Rock, AR, USA. ${ }^{8}$ Kolstan, Övre Kolstan, 67198 Gunnarskog, Sweden.

Received: 3 July 2021 Accepted: 16 February 2022

Published online: 28 February 2022

\section{References}

1. Kylmä J. Despair and hopelessness in the context of HIV-a meta-synthesis on qualitative research findings. J Clin Nurs. 2005;14:813-21.

2. Moosa MYH, Jeemah FY. Feelings of hopelessness in stable HIV-positive patients on antiretrovirals. S Afr J HIV Med. 2010;11:40-4. 
3. Pompili M, Pennica A, Serafini G, Battuello M, Innamoratir M, Teti E, et al. Depression and affective temperaments are associated with poor healthrelated quality of life in patients with HIV infection. J Psychiatr Practi. 2013;19:109-17

4. Mitchell UA, Gutierrez-Kapheim M, Nguyen AW, Al-Amin N. Hopelessness among middle-aged and older blacks: the negative impact of discrimination and protecting power of social and religious resources. Innov Aging. 2020. https://doi.org/10.1093/geroni/igaa044.

5. Robinson MA, Kim I, Mowbray O, Washington T. The effects of hopelessness on chronic disease among African Americans and Caribbean Blacks: findings from the National Survey of American Life (NSAL). Community Ment Health. 2020;56:753-9.

6. Korkmaz H, Korkmaz S, Cakar M. Suicide risk in chronic heart failure patients and its association with depression, hopelessness and self esteem. J Clin Neurosci. 2019;68:51-4.

7. American Psychiatric Association. Diagnostic and statistical manual of mental disorders. 5th ed. Arlington: American Psychiatric Publishing; 2013.

8. Abramson LY, Metalsky GI, Alloy LB. Hopelessness depression: a theorybased subtype of depression. Psychol Rev. 1989:96:358-72.

9. Bonner RL, Rich AR. Predicting vulnerability to hopelessness. A longitudinal analysis. J Nerv Ment Dis. 1991;179:29-32.

10. Beck AT, Weissman A, Lester $D$, Trexler L. The measurement of pessimism: the Hopelessness scale. J Consult Clin Psychol. 1974;42:861-5.

11. Johnson JG, Alloy LBP, Panzarella C, Metalsky GI, Rabkin JG, Williams $J B$, et al. Hopelessness as a mediator of the association between social support and depressive symptoms: findings of a study of men with HIV. J Consult Clin Psychol. 2001;69:1056-60

12. Lee RS, Kochman A, Sikkema KJ. Internalized stigma among people living with HIV-AIDS. AIDS Beh. 2002;6:309-19.

13. Siril H, Smith Fawzi MC, Todd J, Wyatt M, Kilewo J, Ware N, et al. Hopefulness fosters affective and cognitive constructs for actions to cope and enhance quality of life among people living with HIV in Dar Es Salaam, Tanzania. J Int Assoc Provid AIDS Care. 2017;16:140-8.

14. Stanley S, Sethuramalingam V, Sathia S. Life satisfaction and pessimism in HIV positive people: a comparative study from India. Psychosoc Rehabil J. 2013;18:95-104.

15. Swindells S, Mohr J, Justis JC, Berman S, Squier C, Wagener MM, et al. Quality of life in patients with human immunodeficiency virus infection: impact of social support, coping style and hopelessness. Int STD AIDS. 1999;10:382-91.

16. Wagner GJ, Ghosh-Dastidar B, Garnett J, Kityo C, Mugyenyi P. Impact of HIV antiretroviral therapy on depression and mental health among clients with HIV in Uganda. Psychosom Med. 2012;74:883-90.

17. Schönnesson LN, Zeluf G, Garcia-Huidobro D, Ross MW, Eriksson LE, Ekström AM. Sexual (dis)satisfaction and its contributors among people living with HIV infection in Sweden. Arch Sex Behav. 2018;47(7):2007-26.

18. Andersson G. Quality of life and sexual health among transgender people and people living with HIV in Sweden. Thesis for doctoral degree. Stockholm: Department of Public Health Sciences, Karolinska Institutet; 2019.

19. Sjögren E. Kristenson M, Lindquist Group. Can gender differences in psychosocial factors be explained by socioeconomic status? Scand J Public Health. 2006;34: 59-68.

20. Matud MP, López-Curbelo M, Fortes D. Gender and psychological wellbeing. Int J Environ Res Public Health. 2019;16(19):3531.

21. Nurullah AS. Gender differences in distress: the mediating influence of life stressors and psychological resources. Asian Soc Sci. 2010;6(5):27-35.

22. Vosvick M, Martin LA, Grant Smith N, Jenkins R. Gender differences in HIVrelated coping and depression. AIDS Beh. 2010;14:390-400.

23. Aish A, Wasserman D. Does Beck's Hopelessness Scale really measure several components? Psychol Med. 2001;31 (2):367-72.

24. Fugl-Meyer AR, Brännholm IB, Fugl-Meyer KS. Happiness and domainspecific life satisfaction in adult northern Swedes. Clin Rehabil. 1991:5:25-33

25. Horowitz M, Wilner N, Alvarez W. Impact of Event scale: a measure of subjective stress. Psychosom Med. 1979:41:209-18.

26. Berger BE, Ferrans CE, Lashley FR. Measuring stigma in people with HIV: psychometric assessment of the HIV stigma scale. Res Nurs Health. 2001;24:518-29.
27. Reinius M, Wettergren L, Wiklander M, Svedhem V, Ekström AM, Eriksson LE. Development of a 12-item short version of the HIV stigma scale. Health Qual Life Outcomes. 2017;15(1):115.

28. Browne MW, Cudeck R. Alternative ways of assessing model fit. In: Bollen KA, Long JS, editors. Testing structural equation models. Newbury Park: Sage; 1993. p. 136-62.

29. Muthén LK, Muthén BO. Mplus user's guide. 7th ed. Los Angeles: Muthén \& Muthén; 2015.

30. Rubin DB. Multiple imputations for nonresponse in surveys. New York: Wiley; 1987.

31. Haatainen K, Tanskanen A, Kylmä J, Honkalampi K, Koivumaa-Honkanen $\mathrm{H}$, Hintikka J, et al. Factors associated with hopelessness: a population study. Int Soc Psychiatry. 2004;50(2):142-52.

32. Beck AT, Steer RA, Ranieri WF. Scale for suicide ideation: psychometric properties of a self-report version. J Clin Psychol. 1988;44(4):499-505.

33. Govender RD, Schlebusch L. Hopelessness, depression and suicidal ideation in HIV-positive persons. S A Psychiatr. 2012;18(1):16-21.

34. Ishida M, Hulse ES, Mahar RK, Gunn J, Atun R, McPake B, et al. The joint effect of physical multimorbidity and mental health conditions among adults in Australia. Prev Chronic Dis. 2020;10(17):E157.

35. Degroote S, Vogelaers D, Vandijck DM. What determines health-related quality of life among people living with HIV: an updated review of the literature. Arc Public Health. 2014;72(1):40.

36. Maguire R, Hankey O, Maguire P. Living well withchronic illness: How social support, loneliness and psychological appraisals relate to well-being in a population based European sample. J Health Pychol. 2021:26(10):1494-507.

37. Orwelius L, Kristenson M, Fredrikson M, Walther S, Sjöberg F. Hopelessness: Independent associations with health-related quality of life and short-term mortality after critical illness: a prospective, multicentre trial. J Crit Care. 2017:41:58-63.

38. Reblin M, Uchino BN. Social and emotional support and its implication for health. Currt Opin Psychiatry. 2008;21(2):201-5.

39. Fekete EM, Williams SL, Skinta MD. Internalized HIV-stigma, loneliness, depressive symptoms and sleep quality in people living with HIV. Psychol Health. 2018;33(3):398-415.

40. Beutel ME, Klein EM, Brähler E, Reiner I, Jünger $C$, Michal M, et al. Loneliness in the general population: prevalence, determinants and relations to mental health. BMC Psychiatry. 2017;17(1):97.

41. National Academies of Science, Engineering, and Medicine. Social isolation and loneliness in older adults: Opportunities for the health care system. Washington, DC: The National Academies Press. 2020; Retrieved from https://www.nap.edu/catalog/25663/social-isolation-and-lonel iness-in-older-adults-opportunities-for-the\#.

42. Balderson BH, Grothaus L, Harrison RG, Mccoy K, Mahoney C, Catz S. Chronic illness burden and quality of life in an aging HIV population. AIDS Care. 2013;25(4):451-8.

43. Frankl V. Man's search for meaning: an introduction to logotherapy. New York: Simon and Schuster; 1962

44. Fromm E. The art of loving. New York: Bantam Books; 1956.

45. Feuillet P, Lert F, Tron L, Aubriere C, Spiri B, DraySpira R. Prevalence of and factors associated with depression among people living with HIV in France. HIV Med. 2016;18(6):383-94.

46. Heywood W, Lyons A. Change in subjective social status following HIV diagnosis and associated effects on mental and physical health among HIV-positive gay men in Australia. Psychol Health. 2017;32(7):860-75.

47. Wagener MN, Van den Dries L, Van Exel J, Miedema HS, Van Gorp ECM, Roelofs PDDM. Determinants of employment in people living with HIV in the Netherlands. J Occup Rehabil. 2018;28(1):45-56.

48. Kagan M, Itzick M, Tal-Katz P. Demographic, psychosocial, and health- and disability-related factors associated with psychological distress among people with physical disabilities. Rehabil Psychol. 2018;63(3):392-9.

49. Earnshaw VA, Quinn DM, Park CL. Anticipated stigma and quality of life among people living with chronic illnesses. Chronic IIIn. 2012;8(2):79-88.

50. Reinius M, Wiklander M, Wettergren L, Svedhem V, Eriksson L. The relationship between stigma and health-related quality of life in people living with HIV who have full access to antiretroviral treatment: an assessment of Earnshaw and Chaudoir's HIV stigma framework using empirical data. AIDS Beh. 2018;22(12):3795-806. 
51. Zimmerman EB, Woolf SH, Blackburn SM, Kimmel AD, Barnes AJ, Bono RS. The case for considering education and health. Urban Educ. 2018;53(6):744-73.

52. The Public Health Agency of Sweden retrieved from https://www.folkh alsomyndigheten.se/folkhalsorapportering-statistik/statistik-a-o/sjukd omsstatistik/hivinfektion/?t=county

53. Mehdiyar M. Experiencing life as migrants living with HIV in Sweden. Doc toral Theses, Institute of Biomedicine, Department of Infectious Diseases, University of Gothenburg, Sahlgrenska Academy; 2019

54. Been SK, Schade A, Bassant N, Kastelijns M, Pogány K, Verbon A. Anxiety, depression and treatment adherence among HIV-infected migrants. AIDS Care. 2019;31(8):979-87.

55. McGowan JA, Sherr L, Rodger AJ, Fisher M, Miners A, Anderson J, et al. Age, time living with diagnosed HIV infection and self-rated health. HIV Med. 2017;18(2):89-103.

56. Sherr L, Nagra N, Kulubya G, Catalan J, Clucas C, Harding R. HIV infection associated post-traumatic stress disorder and post-traumatic growth-A systematic review. Psychol Health Med. 2011;16:612-29.

57. Van Bilsen WPH, Zimmermann HML, Boyd A, Davidovich U. Burden of living with HIV among men who have sex with men: a mixed-methods survey. Lancet HIV. 2020. https://doi.org/10.1016/S2352-3018(20)30197-1.

\section{Publisher's Note}

Springer Nature remains neutral with regard to jurisdictional claims in published maps and institutional affiliations.

- fast, convenient online submission

- thorough peer review by experienced researchers in your field

- rapid publication on acceptance

- support for research data, including large and complex data types

- gold Open Access which fosters wider collaboration and increased citations

- maximum visibility for your research: over $100 \mathrm{M}$ website views per year

At BMC, research is always in progress.

Learn more biomedcentral.com/submissions 